\title{
DETERMINACIÓN DE LA SUSCEPTIBILIDAD ANTIBIÓTICA in vitro DE BACTERIAS SUBGINGIVALES EN CANINOS CON ENFERMEDAD PERIODONTAL MODERADAASEVERA
}

\section{Antibiotic in vitro Susceptibility of Subgingival Bacteria in Canines with Moderate to Severe Periodontal Disease}

\author{
Henry Vega B. ${ }^{1}$, Viviana Fernández P. ${ }^{2}$, Siever Morales C. ${ }^{1,3}$, \\ Sonia Calle E. ${ }^{1}$, Carlos Pérez C. ${ }^{1}$
}

\section{Resumen}

\begin{abstract}
Se determinó la susceptibilidad antibiótica de bacterias subgingivales en caninos con enfermedad periodontal moderada a severa. Se trabajó con 30 canes provenientes de cuatro albergues de la ciudad de Lima. Las muestras se tomaron con puntas de papel estéril colocadas en el fondo de la bolsa periodontal del cuarto premolar y canino del cuadrante superior derecho. El agente bacteriano aislado con mayor frecuencia fue Porphyromonas gingivalis (50\%). Además, se hallaron Bifidobacterium spp (20\%), Prevotella intermedia (16.7\%), Staphylococcus spp (30\%) y enterobacterias (60\%). La mayor susceptibilidad antibiótica de las especies halladas fue frente al imipenem (100\%), habiendo una susceptibilidad variable para los demás antibióticos dependiendo del agente bacteriano.
\end{abstract}

Palabras clave: enfermedad periodontal, susceptibilidad antibiótica, perros, frecuencia, antibiograma

\section{Abstract}

The aim of this study was to determine the antibiotic susceptibility of subgingival bacteria in dogs with moderate to severe periodontal disease. Thirty dogs from four shelters were sampled using sterile paper sheet tips at the bottom of the periodontal pocket in the fourth premolar and canine teeth of the upper right quadrant. The most

\footnotetext{
${ }^{1}$ Laboratorio de Microbiología y Parasitología Veterinaria, ${ }^{2}$ Clínica de Animales Menores, Facultad de Medicina Veterinaria, Universidad Nacional Mayor de San Marcos, Lima

${ }^{3}$ E-mail: sieverm@gmail.com
}

Recibido: 16 de febrero de 2013

Aceptado para publicación: 20 de setiembre de 2013 
frequent bacteria isolated were Porphyromonas gingivalis (50\%), Bifidobacterium spp (20\%), Prevotella intermedia (16.7\%), Staphylococcus spp (30\%) and enterobacteria $(60 \%)$. The highest antibiotic susceptibility from isolated bacteria species was against imipenem. The susceptibility against other antibiotics depended of the bacterial species.

Key words: periodontal disease, antibiotic susceptibility, dogs, frequency, antibiogram

\section{INTRODUCCIÓN}

La enfermedad periodontal engloba a los procesos patológicos que afectan los tejidos de soporte de los dientes, desde la inflamación de la encía (gingivitis) hasta su extensión hacia el ligamento periodontal y el hueso adyacente, dando lugar a la aparición de bolsas periodontales y provocando una pérdida ósea y de inserción progresiva (periodontitis) (American Academy of Periodontology, 1999).

Es bien aceptado dentro de la comunidad odontológica que los resultados de la enfermedad periodontal no solo se dan por la simple acumulación de volumen de placa dental, sino también por el crecimiento y dominio de determinados organismos patológicos tras el desarrollo complejo de la placa (Page y Schroeder, 1976). Si el problema dental no es tratado a tiempo, las bacterias periodontales pueden extenderse a otros sitios del cuerpo, causando una bacteriemia (Nieves et al., 1997) y conducir a enfermedad renal, coronaria o hepática (De Bowes et al., 1996).

Aunque la enfermedad periodontal puede ser controlada por remoción mecánica de los depósitos dentales y manejo de las bolsas periodontales, la literatura apoya la intervención antimicrobiana como parte del tratamiento (Zetner y Thiemann, 1993; Killoy y Polson, 1998; De Bowes, 2002; Nielsen et al., 2000; Slots y Ting, 2002; Zetner y Rothmüller, 2002). La administración de antibióticos preoperatorios se orienta a reducir la inflamación antes de la terapia periodontal, reducir la bacteriemia en el momento del tratamiento y establecer un tejido más sano para las labores del cirujano, mientras que en el posoperatorio se apunta a optimizar la curación de los tejidos reduciendo la carga microbiana (Gorrel, 2004).

Aunque los cultivos y la prueba de sensibilidad son raramente realizados en pacientes que tienen una infección que se extiende en la cavidad oral, la selección de un antibiótico apropiado debe basarse en información existente sobre la sensibilidad de los patógenos orales conocidos (Radice et al., 2006).

El propósito del presente estudio fue determinar la susceptibilidad antibiótica de las bacterias subgingivales presentes en caninos con enfermedad periodontal, proporcionando información útil al clínico para el tratamiento antimicrobiano de esta patología.

\section{Materiales y Métodos}

\section{Animales y Muestras}

Se trabajó con 30 canes con diagnóstico de enfermedad periodontal moderada a severa de acuerdo al índice veterinario periodontal de Wiggs y Lobprise (1997). Los canes eran de raza y edad variada, de ambos sexos y alimentados con comida casera, provenientes de cuatro albergues caninos. Animazul del distrito de Pachacamac, Claudia Toledano de Los Olivos, María Esther Murillo de El Callao y Adopta una Mascota de San Juan de Lurigancho, Lima. 
La toma de muestras se realizó con puntas de papel estéril colocadas en el fondo de las bolsas periodontales de los dientes cuarto premolar superior derecho y canino superior derecho. Se colocaron cuatro puntas de papel por diente de forma consecutiva y por un tiempo de 20 segundos cada una. Las dos primeras se colocaron en tubos con caldo tioglicolato y las dos restantes en tubos con caldo tripticasa soya (TSB). Las muestras fueron procesadas en el Laboratorio de Bacteriología de la Facultad de Medicina Veterinaria (FMV) de la Universidad Nacional Mayor de San Marcos (UNMSM), Lima.

\section{Detección de Bacterias Anaerobias}

Las muestras fueron sembradas en placas de agar sangre e incubadas a $37{ }^{\circ} \mathrm{C}$ por 14 días en jarras de anaerobiosis, para permitir el crecimiento de colonias bacterianas de desarrollo lento (Khemaleelakul y Baumgartner, 2002). Se hizo una clasificación preliminar de las bacterias, basado en las características macroscópicas de las colonias y el resultado de la tinción Gram como cocos gram positivos, cocos gram negativos, bacilos gram positivos y bacilos gram negativos.

Las colonias fueron resembradas en placas de agar sangre por 14 días y en condiciones de anaerobiosis a fin de obtener cultivos puros. Las colonias resultantes fueron coloreadas con la tinción gram para corroborar la pureza de la cepa, y en los casos de duda se hizo una resiembra. Las bacterias aisladas y purificadas fueron identificadas utilizando las galerías del sistema API 20A (BioMérieux, Francia), siguiendo las recomendaciones del fabricante. Las galerías fueron incubadas a $37{ }^{\circ} \mathrm{C}$ por 48 horas en condiciones de anaerobiosis.

\section{Detección de Bacterias Aerobias}

La siembra se realizó en el medio selectivo agar McConkey y en un medio general, agar sangre (agar tripticasa soya más 5\% de sangre desfibrinada de ovino). Las placas se incubaron por $24 \mathrm{~h}$ a $37^{\circ} \mathrm{C}$. Con las colonias resultantes se procedió con las técnicas de coloración de apoyo (tinción gram) y pruebas bioquímicas (catalasa, oxidasa, coagulasa, citrato de Simons, triple azúcar hierro, urea, lisina, sulfuro, indol, motilidad, nitrato), para llegar al diagnóstico de la bacteria.

\section{Prueba de Susceptibilidad Antibiótica}

Las pruebas de sensibilidad se realizaron por el método de difusión en disco de Kirby-Bauer (Kirby y Bauer, 1966). Se inoculó una cantidad estandarizada de bacterias en solución salina ( 0.5 de la escala de McFarland). Los inóculos fueron sembrados con hisopos estériles dentro de los 15 minu-

Cuadro 1. Frecuencia de microorganismos aislados en 30 caninos con enfermedad periodontal moderada a se vera

\begin{tabular}{lcc}
\hline \multirow{2}{*}{ Agente } & \multicolumn{2}{c}{ Frecuencia } \\
\cline { 2 - 3 } & $\mathrm{n}$ & $\%$ \\
\hline Porphyromonas gingivalis & 15 & 50.0 \\
Escherichia coli & 12 & 40.0 \\
Staphylococcus aureus & 9 & 30.0 \\
Bifidobacterium spp & 6 & 20.0 \\
Enterobacter aerogenes & 6 & 20.0 \\
Prevotella intermedia & 5 & 16.7 \\
Fusobacterium nucleatum & 3 & 10.0 \\
Porphyromonas & 2 & 6.7 \\
$\quad$ asaccharolytica & 2 & 6.7 \\
Bacteroides ovatus & 2 & 6.7 \\
Staphylococcus & 2 & 6.7 \\
$\quad$ saccharolyticus & 2 & 6.7 \\
Proteus mirabilis & 2 & 6.7 \\
Proteus vulgaris & 1 & 3.3 \\
Actinomices viscosus & 1 & 3.3 \\
Prevotella oralis & 1 & 3.3 \\
Bacteroides fragilis & 1 & 3.3 \\
Shigella spp & 1 & 3.3 \\
Citrobacter spp & 1 & 3.3 \\
Corynebacterium & 1 & 3.3 \\
Actinomices naeslundii & 1 & 3.3 \\
Pseudomona aeruginosa & 1 & 3.3 \\
Bacillus subtilis & 77 & 100 \\
Bacillus spp & & \\
Total &
\end{tabular}


tos de preparados utilizando agar Mueller Hinton y en casos de crecimiento inadecuado en agar sangre. El sembrado se realizó en tres direcciones asegurando una buena distribución del inóculo y que las zonas de inhibición sean uniformemente circulares.

Luego de cinco minutos, con una pinza estéril se colocaron los discos de papel filtro impregnados con concentraciones conocidas de antibióticos. Las placas fueron incubadas por $24 \mathrm{~h}$ a $37^{\circ} \mathrm{C}$ en aerobiosis o anaerobiosis, según la cepa identificada, y se midieron los halos de inhibición de desarrollo, interpretándolos de acuerdo a las tablas del Comité Nacional para Estándares de Laboratorio Clínico (NCCLS). La susceptibilidad de los microorganismos a los agentes antimicrobianos se calificaron como sensible, intermedia o resistente.

Los discos de sensibilidad (Andina Médica S.A.) utilizados se encuentran agrupados dentro de las siguientes familias:
- $\beta$-lactámicos: penicilina, ampicilina, amoxicilina, cefalotina, cefalexina, ceftriaxona, cefoxitina, imipenem

- Fluoroquinolonas: ciprofloxacina, enrofloxacina

- Tetraciclinas: oxitetraciclina, doxiciclina

- Aminoglucósidos: gentamicina

- Lincosamidas: clindamicina

- Anfenicoles: cloranfenicol

- Nitroimidazoles: metronidazol

- Antibióticos asociados: amoxicilina más ácido clavulánico y sulfatrimetoprim

\section{Resultados}

Los microorganismos más prevalentes fueron Porphyromonas gingivalis, Escherichia coli y Staphylococcus aureus, Bifidobacterium spp, Enterobacter aerogenes y Prevotella intermedia (Cuadro 1).

Cuadro 2. Susceptibilidad antibiótica de Porphyromonas gingivalis en caninos con enfermedad periodontal moderada a severa ( $\mathrm{n}=15$ muestras positivas)

\begin{tabular}{lcccccc}
\hline \multirow{2}{*}{ Antibiótico } & \multicolumn{7}{c}{ Condición } \\
\cline { 2 - 7 } & \multicolumn{2}{c}{ Sensible } & \multicolumn{2}{c}{ Intermedio } & \multicolumn{2}{c}{ Resistente } \\
\cline { 2 - 7 } & $\mathrm{n}$ & $\%$ & $\mathrm{n}$ & $\%$ & $\mathrm{n}$ & $\%$ \\
\hline Imipenem & 15 & 100.0 & - & - & - & - \\
Amoxicilina + ácido clavulánico & 14 & 93.3 & 1 & 6.7 & - & - \\
Clindamicina & 14 & 93.3 & 1 & 6.7 & - & - \\
Metronidazol & 14 & 93.3 & 1 & 6.7 & - & - \\
Ceftriaxona & 13 & 86.7 & 2 & 13.3 & - & - \\
Doxiciclina & 13 & 86.7 & 2 & 13.3 & - & - \\
Cloranfenicol & 13 & 86.7 & 2 & 13.3 & - & - \\
Oxitetraciclina & 12 & 80.0 & 3 & 20.0 & - & - \\
Cefoxitina & 12 & 80.0 & 3 & 20.0 & - & - \\
Ciprofloxacina & 8 & 53.3 & 6 & 40.0 & 1 & 6.7 \\
Enrofloxacina & 7 & 46.7 & 7 & 46.7 & 1 & 6.7 \\
Amoxicilina & 7 & 46.7 & 7 & 46.7 & 1 & 6.7 \\
Ampicilina & 6 & 40.0 & 6 & 40.0 & 3 & 20.0 \\
Penicilina & 5 & 33.3 & 7 & 46.7 & 3 & 20.0 \\
Cefalexina & 5 & 33.3 & 7 & 46.7 & 3 & 20.0 \\
Cefalotina & 4 & 26.7 & 8 & 53.3 & 3 & 20.0 \\
Sulfatrimetropin & - & - & 8 & 53.3 & 7 & 46.7 \\
Gentamicina & - & - & - & - & 15 & 100.0 \\
\hline & & & & & & \\
\hline
\end{tabular}


La cepas de Porphyromonas gingivalis fueron sensibles a la mayoría de los antibacterianos, con frecuencias de sensibilidad entre 53.3 a $100 \%$. Los antibióticos con mayor sensibilidad (>80\%) fueron imipenem, amoxicilina + ácido clavulánico, clindamicina, metronidazol, ceftriaxona, doxiciclina y cloranfenicol, mientras que los mayores índices de resistencia se observaron frente a sulfatrimetropin $(46.7 \%)$ y gentamicina (100\%) (Cuadro 2).

La frecuencia de susceptibilidad antibiótica de Bifidobacterium spp se muestra en el Cuadro 3. Se encontró alta sensibilidad $(>80 \%)$ a imipenem, ceftriazona, amoxicilina + ácido clavulánico, amoxicilina y clindamicina e índices de resistencia elevados a sulfatrimetropin y gentamicina. En el caso de las cepas de Prevotella intermedia, los antibióticos imipenem y ceftriaxona mostraron una sensibilidad de $100 \%$, en tanto que los mayores índices de resistencia fueron frente a sulfatrimetropin y gentamicina (Cuadro 4).

En el caso de Staphylococcus aureus, con nueve antibiogramas, se encontró que el antibiótico de mayor sensibilidad fue imipenem $(100 \%)$ y el de mayor resistencia fue la penicilina (Cuadro 5). Asimismo, en el caso de los 12 antibiogramas contra cepas de Escherichia coli se tuvo que el antibiótico con más alta sensibilidad fue imipenem (91.7\%), mientras que los mayores índices de resistencia fueron frente a oxitetraciclina y penicilina (Cuadro 6).

Cuadro 3. Susceptibilidad antibiótica de Bifidobacterium spp en caninos con enfermedad periodontal moderada a severa ( $\mathrm{n}=6$ muestras positivas)

\begin{tabular}{lcccccc}
\hline \multirow{2}{*}{ Antibiótico } & \multicolumn{9}{c}{ Condición } \\
\cline { 2 - 7 } & \multicolumn{2}{c}{ Sensible } & \multicolumn{2}{c}{ Intermedio } & \multicolumn{2}{c}{ Resistente } \\
\cline { 2 - 7 } & $\mathrm{n}$ & $\%$ & $\mathrm{n}$ & $\%$ & $\mathrm{n}$ & $\%$ \\
\hline Imipenem & 6 & 100.0 & - & - & - & - \\
Ceftriaxona & 6 & 100.0 & - & - & - & - \\
Amoxicilina + ácido clavulánico & 5 & 83.3 & 1 & 16.7 & - & - \\
Amoxicilina & 5 & 83.3 & 1 & 16.7 & - & - \\
Clindamicina & 5 & 83.3 & 1 & 16.7 & - & - \\
Cefoxitina & 4 & 66.7 & 2 & 33.3 & - & - \\
Doxiciclina & 4 & 66.7 & 2 & 33.3 & - & - \\
Penicilina & 4 & 66.7 & 2 & 33.3 & - & - \\
Cefalexina & 4 & 66.7 & 2 & 33.3 & - & - \\
Cefalotina & 4 & 66.7 & 2 & 33.3 & - & - \\
Ciprofloxacina & 3 & 50.0 & 3 & 50.0 & - & - \\
Enrofloxacina & 3 & 50.0 & 3 & 50.0 & - & - \\
Oxitetraciclina & 3 & 50.0 & 3 & 50.0 & - & - \\
Ampicilina & 3 & 50.0 & 3 & 50.0 & - & - \\
Metronidazol & 3 & 50.0 & 3 & 50.0 & - & - \\
Cloranfenicol & 2 & 33.3 & 4 & 66.7 & - & - \\
Sulfatrimetropin & - & - & 3 & 50.0 & 3 & 50.0 \\
Gentamicina & - & - & - & - & 6 & 100.0 \\
\hline
\end{tabular}


Cuadro 4. Susceptibilidad antibiótica de Prevotella intermedia en caninos con enfermedad periodontal moderada a severa ( $\mathrm{n}=5$ muestras positivas)

\begin{tabular}{lcccccc}
\hline \multirow{2}{*}{ Antibiótico } & \multicolumn{7}{c}{ Condición } \\
\cline { 2 - 7 } & \multicolumn{2}{c}{ Sensible } & \multicolumn{2}{c}{ Intermedio } & \multicolumn{2}{c}{ Resistente } \\
\cline { 2 - 7 } & $\mathrm{n}$ & \multicolumn{1}{c}{$\%$} & $\mathrm{n}$ & $\%$ & $\mathrm{n}$ & $\%$ \\
\hline Imipenem & 5 & 100.00 & - & - & - & - \\
Ceftriaxona & 5 & 100.0 & - & - & - & - \\
Cefoxitina & 4 & 80.0 & 1 & 20.0 & - & - \\
Amoxicilina + ácido clavulánico & 4 & 80.0 & 1 & 20.0 & - & - \\
Clindamicina & 4 & 80.0 & 1 & 20.0 & - & - \\
Cloranfenicol & 4 & 80.0 & 1 & 20.0 & - & - \\
Doxiciclina & 4 & 80.0 & 1 & 20.0 & - & - \\
Oxitetraciclina & 3 & 60.0 & 2 & 40.0 & - & - \\
Metronidazol & 3 & 60.0 & 2 & 40.0 & - & - \\
Cefalotina & 2 & 40.0 & 2 & 40.0 & 1 & 20.0 \\
Ciprofloxacina & 2 & 40.0 & 2 & 40.0 & 1 & 20.0 \\
Enrofloxacina & 2 & 40.0 & 2 & 40.0 & 1 & 20.0 \\
Ampicilina & 2 & 40.0 & 1 & 20.0 & 2 & 40.0 \\
Amoxicilina & 2 & 40.0 & 1 & 20.0 & 2 & 40.0 \\
Cefalexina & 2 & 40.0 & 1 & 20.0 & 2 & 40.0 \\
Penicilina & 1 & 20.0 & 2 & 40.0 & 2 & 40.0 \\
Sulfatrimetropin & - & - & 2 & 40.0 & 3 & 60.0 \\
Gentamicina & - & - & - & - & 5 & 100.0 \\
\hline
\end{tabular}

Cuadro 5. Susceptibilidad antibiótica de Staphylococcus aureus en caninos con enfermedad periodontal moderada a severa ( $\mathrm{n}=9$ muestras positivas)

\begin{tabular}{lcccccc}
\hline \multirow{2}{*}{ Antibiótico } & \multicolumn{7}{c}{ Condición } \\
\cline { 2 - 8 } & \multicolumn{2}{c}{ Sensible } & \multicolumn{2}{c}{ Intermedio } & \multicolumn{2}{c}{ Resistente } \\
\cline { 2 - 7 } & $\mathrm{n}$ & $\%$ & $\mathrm{n}$ & $\%$ & $\mathrm{n}$ & $\%$ \\
\hline Imipenem & 9 & 100.0 & - & - & - & - \\
Amoxicilina + ácido clavulánico & 7 & 77.8 & 1 & 11.1 & 1 & 11.1 \\
Amoxicilina & 7 & 77.8 & 1 & 11.1 & 1 & 11.1 \\
Ceftriaxona & 6 & 66.7 & 3 & 33.3 & - & - \\
Enrofloxacina & 6 & 66.7 & 2 & 22.2 & 1 & 11.1 \\
Sulfatrimetropin & 5 & 55.6 & 3 & 33.3 & 1 & 11.1 \\
Cefoxitina & 5 & 55.6 & 4 & 44.4 & - & - \\
Cefalotina & 5 & 55.6 & 2 & 22.2 & 2 & 22.2 \\
Gentamicina & 5 & 55.6 & 4 & 44.4 & - & - \\
Ciprofloxacina & 4 & 44.4 & 5 & 55.6 & - & - \\
Cefalexina & 4 & 44.4 & 3 & 33.3 & 2 & 22.2 \\
Doxiciclina & 4 & 44.4 & 3 & 33.3 & 2 & 22.2 \\
Cloranfenicol & 3 & 33.3 & 4 & 44.4 & 2 & 22.2 \\
Clindamicina & 3 & 33.3 & 2 & 22.2 & 4 & 44.4 \\
Oxitetraciclina & 2 & 22.2 & 3 & 33.3 & 4 & 44.4 \\
Ampicilina & 1 & 11.1 & 1 & 11.1 & 7 & 77.8 \\
Penicilina & - & - & - & - & 9 & 100.0 \\
\hline
\end{tabular}


Cuadro 6. Susceptibilidad antibiótica de Escherichia coli en caninos con enfermedad periodontal moderada a severa ( $\mathrm{n}=12$ mue stras positivas)

\begin{tabular}{lcccccc}
\hline \multirow{2}{*}{ Antibiótico } & \multicolumn{7}{c}{ Condición } \\
\cline { 2 - 7 } & \multicolumn{2}{c}{ Sensible } & \multicolumn{2}{c}{ Intermedio } & \multicolumn{2}{c}{ Resistente } \\
\cline { 2 - 7 } & $\mathrm{n}$ & $\%$ & $\mathrm{n}$ & $\%$ & $\mathrm{n}$ & $\%$ \\
\hline Imipenem & 11 & 91.7 & 1 & 8.3 & - & - \\
Sulfatrimetropin & 9 & 75 & 3 & 25.0 & - & - \\
Amoxicilina + ácido clavulánico & 9 & 75 & 2 & 16.7 & 1 & 8.3 \\
Gentamicina & 9 & 75 & 2 & 16.7 & 1 & 8.3 \\
Ceftriaxona & 8 & 66.7 & 4 & 33.3 & - & - \\
Cloranfenicol & 8 & 66.7 & 4 & 33.3 & - & - \\
Ciprofloxacina & 8 & 66.7 & 2 & 16.7 & 2 & 16.7 \\
Cefoxitina & 7 & 58.3 & 5 & 41.7 & - & - \\
Enrofloxacina & 7 & 58.3 & 3 & 25.0 & 2 & 16.7 \\
Doxiciclina & 5 & 41.7 & 5 & 41.7 & 2 & 16.7 \\
Amoxicilina & 3 & 25 & 7 & 58.3 & 2 & 16.7 \\
Oxitetraciclina & 3 & 25 & 4 & 33.3 & 5 & 41.7 \\
Cefalexina & 1 & 8.3 & 10 & 83.3 & 1 & 8.3 \\
Cefalotina & 1 & 8.3 & 8 & 66.7 & 3 & 25.0 \\
Ampicilina & 1 & 8.3 & 7 & 58.3 & 4 & 33.3 \\
Penicilina & - & - & 6 & 50.0 & 6 & 50.0 \\
\hline
\end{tabular}

\section{Discusión}

La mayoría de perros de más de cinco años de edad se encuentran afectados por periodontitis (Harvey, 1998). A medida que se desarrolla la gingivitis, la placa se extiende a nivel subgingival, los aerobios consumen oxígeno y se genera un potencial redox reducido, originando un ambiente más favorable para la proliferación de las especies anaeróbicas (Harvey, 2005). Bacterias de los géneros Porphyromonas y Prevotella están firmemente implicadas como patógenos periodontales en el ser humano, e igual sucede en el caso de la enfermedad periodontal canina (Harvey et al., 1995; Harvey, 1998). En el presente estudio, $P$. gingivalis fue detectado en el 50\% de la población evaluada y fue la bacteria anaerobia que se aisló con mayor frecuencia. Por su parte, Allaker et al. (1997) y Nishiyama et al. (2007) encontraron esta bacteria en el 68 y $64 \%$ en perros con periodontitis, respectivamente.
Syed et al. (1981) reportaron un predominio de Porphyromonas asaccharolytica y Fusobacterium nucleatum en bolsas periodontales profundas de 15 perras Beagle alimentadas con comida balanceada; sin embargo, la frecuencia de estas especie en el presente estudio fue relativamente baja (Cuadro 1). Bifidobacterium spp fue la segunda especie, dentro de las cepas anaerobias, más frecuentemente aislada (20\%). Este porcentaje es comparable con los resultados de Newman et al. (1977) con muestras de flora subgingival de perros Beagle alimentados con dieta blanda.

En forma similar, bacterias del género Prevotella se aislaron en $20 \%$ de los perros, siendo $P$. intermedia la de mayor frecuencia dentro de este género. Esta frecuencia es comparable con los reportes de Nishiyama et al. (2007) en perros con periodontitis y de Radice et al. (2006) en perros con enfermedad periodontal. Aislamientos de P. intermedia son comúnmente encontrados en la cavi- 
dad oral de personas con salud periodontal o sin ella, así como en aquellos con infecciones extra orales (Jousimies-Somer et al., 1993); habiéndose demostrado que estas bacterias pueden colonizar cónyuges o padres e hijos (Fukui et al., 1999), y lo mismo podría ocurrir entre propietarios y los canes domésticos, debido a que estos animales tienen una estrecha relación con los activistas responsables de los albergues.

Bacterias del género Actinomyces (A. viscosus y A. naeslundii) fueron encontradas en una baja frecuencia, concordando con los hallazgos de Syed et al. (1981) en flora subgingival y supragingival de perros Beagle con gingivitis, así como con el estudio de Svanberg et al. (1982) en muestras de bolsas periodontales.

Newman et al. (1977) encontraron que los cocos facultativos, fundamentalmente Streptococcus y Staphylococcus, estaban presentes en el 3.4\% de lesiones periodontales avanzadas ( $>4 \mathrm{~mm}$ de pérdida de hueso). Sin embargo, en el presente estudio, no se identificaron especies de Streptococcus pero se aislaron cepas de Staphylococcus (S. aureus y $S$. saccharolyticus) en el $36.7 \%$ de las muestras. La razón de la prevalencia excepcionalmente alta de $S$. aureus (30\%) no está clara. Esta bacteria constituye parte de la microflora de la piel y de las mucosas del hombre y la literatura menciona la posibilidad de zooantropozoonosis causadas por esos microrganismos (Simoons-Smit et al., 2000).

En el presente estudio, los bacilos entéricos gram negativos estuvieron presentes en el $80 \%$ de las muestras, siendo Escherichia coli la de mayor frecuencia (40\%). Este hallazgo no ha sido reportado en otros estudios con excepción del realizado por Krasse y Brill (1960). En el caso de peridontitis humana crónica, se han identificado microorganismos inusuales en la placa subgingival que incluyen bacilos entéricos gram negativos y levaduras (Ardila y Guzmán, 2012). No obstante, la frecuencia de este fenómeno es muy diversa (Souto y Colombo,
2008), pero existe la posibilidad que este fenómeno también se desarrolle en caninos. Ciertas condiciones del microambiente oral podrían facilitar el crecimiento exacerbado de estos patógenos oportunistas, entre ellas, las condiciones higiénico sanitarias deficientes de los albergues, hábitos de coprofagia y el lamido frecuente de la zona anal.

Los microorganismos inusuales, al encontrarse junto con los organismos periodontopáticos en el microambiente de la bolsa periodontal pueden aprovecharse de condiciones como nutrientes, protección ante la respuesta inmune y economía en el gasto energético (Socransky y Haffajee, 2002). Sin embargo, no se han descrito con claridad los tipos de interrelaciones microbianas que puedan existir entre ambos tipos de patógenos a nivel de la microbiota subgingival.

Los antibióticos que presentan mayores índices de sensibilidad frente a Porphyromonas gingivalis fueron, en orden decreciente, imipenem, amoxicilina + ácido clavulánico, clindamicina y metronidazol, entre otros. Contrario a lo anteriormente descrito, se encontró alta resistencia de todas las cepas frente a gentamicina, lo cual podría ser explicado por la resistencia natural de las bacterias anaerobias frente a esta familia de antibióticos, dado que carecen de sistemas de transporte necesarios para captar a los aminoglucósidos a través de su membrana citoplasmática (García y García, 1997).

Frente a Prevotella intermedia se encontró alta sensibilidad a imipenem y ceftriaxona. El espectro antimicrobiano de los carbapenémicos cubre la mayoría de los gérmenes gram positivos y negativos, tanto aerobios como anaerobios, lo cual los convierte en una buena opción para la terapia adyuvante de la enfermedad periodontal. Así mismo, la ceftriaxona, cefalosporina de tercera generación, y antimicrobiano de amplio espectro y alta resistencia frente a cepas productoras de â-lactamasas (Sumano, 2006), también se muestra como una buena alternativa. La desventaja de ambos radica en que 
deben ser aplicados por vía intramuscular o intravenosa, lo cual limitaría su uso en tratamientos prolongados.

Las cepas de Bifidobacterium spp fueron sensibles a la mayoría de los antibacterianos empleados. Algo similar ocurrió con las cepas de Staphylococcus aureus, aunque en este caso los mayores índices de resistencia se dieron frente a ampicilina $(77.8 \%)$ y penicilina $(100 \%)$. La resistencia a las penicilinas viene dada por la producción de la enzima penicilinasa que está bajo el control de un plásmido y es un hecho tan generalizado, que actualmente se prescinde de este antibiótico para tratar infecciones causada por este germen (Nodarse, 2001).

Con respecto a Escherichia coli, las pruebas de susceptibilidad antibacteriana al imipenem (91.7\%) mostraron los índices más altos. Sulfatrimetropin, amoxicilina más ácido clavulánico, gentamicina, ceftriaxona, cloranfenicol, ciprofloxacina, cefoxitina y enrofloxacina también demostraron índices de susceptibilidad mayores a 50\%. El mayor índice de resistencia fue observado frente a penicilina (50\%). Antibióticos como ampicilina $(33.3 \%)$, oxitetraciclina $(41.7 \%)$ y cefalotina (25\%), también presentaron niveles considerables de resistencia, superando los índices de sensibilidad antimicrobiana. El principal mecanismo de resistencia a los â-lactámicos en bacterias gram negativas involucra a las â-lactamasas, enzimas periplásmicas capaces de hidrolizar el anillo â-lactámico de dichos antibióticos, con lo cual pierden su actividad.

La presentación de resistencia observada frente a otros antibióticos de amplio espectro podría estar asociada a la transferencia de plásmidos mediante mecanismos de intercambio de $\mathrm{ADN}$ bacteriano (transformación, conjugación y transducción). Estos pueden transferir información entre bacterias de especies distintas e incluso de géneros diferentes. Las enterobacterias comparten un hábitat ecológico con un amplio rango de especies gram positivas y gram negativas en el espacio subgingival, por lo que están expuestos a un amplio grupo de genes de resistencia.

Harvey (2005) demostró que mientras la patología cambia de gingivitis a periodontitis, el número total de aerobios viables no cambia, pero la proporción anaeróbicas/aeróbicas aumenta con predominancia de anaerobios. Una reducción de la tensión de oxígeno causada por la proliferación de la flora aeróbica crea condiciones favorables de crecimiento para los anaerobios.

Los resultados del presente estudio indican que imipenem podría ser eficaz para el tratamiento antimicrobiano de esta patología. Así mismo, el uso de combinaciones antibióticas se presenta como una alternativa válida, siendo las combinaciones más efectivas amoxicilina con ácido clavulánico más gentamicina, clindamicina más gentamicina, metronidazol más gentamicina (no cubre cepas de Bifidobacterium), doxiciclina o oxitetraciclina más gentamicina (no cubre Bacteroides fragilis ni Staphylococcus saccharolyticus), cloranfenicol más gentamicina (no cubre Staphylococcus saccharolyticus ni Bifidobacterium), cefoxitina más gentamicina (no cubre Staphylococcus saccharolyticus).

Estudios relacionados a la determinación de la susceptibilidad antibiótica de bacterias subgingivales en caninos con enfermedad periodontal no han sido realizados hasta el momento en el país. Los antibióticos que mostraron mayores índices de sensibilidad deberán ser tomados en cuenta para las pruebas de susceptibilidad futuras y en la terapia antimicrobiana en caso de no contar con un laboratorio para procesar las muestras en la brevedad del caso evitando así, el uso y abuso indiscriminado de drogas y la aparición de nuevas resistencias a los antibióticos. 


\section{Conclusiones}

- El agente aislado con mayor frecuencia en caninos con enfermedad periodontal moderada a severa fue Porphyromonas gingivalis, seguido de Escherichia coli, Staphylococcus aureus, Bifidobacterium spp, Enterobacter aerogenes y Prevotella intermedia.

- Los niveles de susceptibilidad antibiótica más elevados para las cepas aisladas se encontraron frente al imipenem, siendo variable para los demás antibióticos probados.

\section{Literatura Citada}

1. Allaker RP, Young KA, Langlois T, Rosayro R, Hardie JM. 1997. Dental plaque flora of the dog with reference to fastidious and anaerobic bacteria associated with bites. J Vet Dent 14: 127130.

2. American Academy of Periodontology. 1999. The pathogenesis of periodontal diseases. J Periodontal 70: 457-470.

3. Ardila C, Guzmán I. 2012. Microorganismos inusuales en placa subgingival de pacientes con periodontitis crónica. AMC (online) 16(2): 153-161 [Internet], [16 febrero 2013]. Disponible en: http:// scielo.sld.cu/scielo.php?script $=$ sci_arttext\&pid=S 1025 02552012000200004.

4. De Bowes L, Mosier D, Logan E, Harvey $C$, Lowry $S$, Richardson $D C$. 1996. Association of periodontal disease and histologic lesions in multiple organs from 45 dogs. $J$ Vet Dent 13: 57-60.

5. De Bowes L. 2002. Odontología: aspectos periodontales. En: Ettinger S, Feldman E (eds). Tratado de medicina interna veterinaria: enfermedades del perro y el gato. $5^{\circ}$ ed. Vol 2. Buenos Aires: Ed InterMédica. p 1249-1258.
6. Fukui K, Kato N, Kato H, Watanabe K, Tatematsu N. 1999. Incidence of Prevotella intermedia and Prevotella nigrescens carriage among family members with subclinical periodontal disease. J Clin Microbiol 37: 3141-3145.

7. García JA, García E. 1997. Resistencias bacterianas y antibioterapia. En: Eficacia in vivo, eficacia in vitro. Madrid: Ed Doyma. p 39-50.

8. Gorrel C. 2004. Periodontal disease. In: Veterinary dentistry for the general practicioner. Philadelphia, USA: Ed Saunders. p 87-110.

9. Harvey C. 1998. Periodontal disease in dogs. Etiopathogenesis, prevalence, and significance. Vet Clin N Am-Small 28: 1111-1128.

10. Harvey C. 2005. Management of Periodontal Disease: Understanding the Options. Vet Clin Small Anim. 35(4): 819 - 836.

11. Harvey C, Thornsberry C, Miller B. 1995. Subgingival bacteria: comparison of culture results in dogs and cats with gingivitis. J Vet Dent 12: 147-150.

12. Jousimies-Somer H, Savolainen S, Makitie A, Ylikoshi J. 1993. Bacteriologic finding in peritonsillar abscesses in young adults. Clin Infect Dis 16:292-298.

13. Khemaleelakul S, Baumgartner $C$. 2002. Identification of bacteria in acute endodontic infections and their antimicrobial susceptibility. Oral Surg Oral Med O 94: 746-755.

14. Killoy WJ, Polson AM. 1998. Administración local controlada de antibacterianos en el tratamiento de la periodontitis. Clínicas de Norteamérica 2: 277297.

15. Kirby W, Bauer A W. 1966. Antibiotic susceptibility testing by standardized single disk method. Am J Clin Pathol, 45: 493-496.

16. Krasse B, Brill N. 1960. Effect of consistency of diet on bacteria in gingival pocket in dogs. Odontol Rev 11: 152-165. 
17. National Committee for Clinical Laboratory Standards [NCCLS]. 1997. Approved standard M2 - A6. Performance standards for antimicrobial disk susceptibility test. 6th ed. Wayne, USA: NCCLS.

18. Newman MG, Sandler M, Ormerod W. 1977. The effect of dietary Gantrisin ${ }^{\circledR}$ supplements on the flora of periodontal pockets in four Beagle dogs. J Periodontol Res 12: 129-134.

19. Nielsen D, Walser C, Kodan GK, Chaney RD, Yonkers T, VerSteeg J, et al. 2000. Effects of treatment with clindamycin hydrochloride on progression of canine periodontal disease after ultrasonic scaling. Vet Ther 1: 150-158.

20. Nieves MA, Hartwig P, Kinyon JM, Riedesel DH. 1997. Bacterial isolates from plaque and from blood during and after routine dental procedures in dogs. Vet Surg 26: 26-32.

21. Nishiyama S, Andrade G, Gioso M, Avila-Campos M. 2007. Detection of putative periodontal pathogens in subgingival specimens of dogs. Braz $\mathbf{J}$ Microbiol 38: 23-28.

22. Nodarse R. 2001. Estafilococos multirresistentes: uso del disco de oxacilín como marcador de resistencia a antibióticos. Rev Cub Med Milit 30(1): 7-10.

23. Page R, Schroeder HE. 1976. Pathogenesis of inflammatory periodontal disease. A summary of current work. Lab Invest 33: 235-249.

24. Radice M, Martino PA, Reiter AM. 2006. Evaluation of subgingival bacteria in the dog and susceptibility to commonly used antibiotics. J Vet Dent 23:219-224.
25. Simoons-Smit A, Salvelkoul P, Stoof J, Starink T, Vandenbroucke-Grauls $C$. 2000. Transmission of Staphylococcus aureus between humans and domestic animals in a household. Eur J Clin Microbiol Infect Dis 19: 150-152.

26. Slots J, Ting M. 2002. Systemic antibiotics in the treatment of periodontal disease. Periodontol 2000 28: 106-176.

27. Socransky SS, Haffajee AD. 2002. Dental biofilms: difficult therapeutic targets. Periodontol 2000 28: 12-55.

28. Souto R, Colombo AP. 2008. Prevalence of Enterococcus faecalis in subgingival biofilm and saliva of subjects with chronic periodontal infection. Arch Oral Biol 53: 155-160.

29. Sumano H. 2006. Farmacología veterinaria. $3^{\circ}$ ed. México DF: McGraw-Hill. $1082 \mathrm{p}$.

30. Svanberg GK, Syed SA, Scott BW. 1982. Differences between gingivitis and periodontitis associated microbiotal flora in the Beagle dog. J Periodont Res 17: 1-11.

31. Syed SA, Svanberg M, Svanberg G. 1981. The predominant cultivable dental plaque flora of beagle dogs with periodontitis. J Periodont Res 8: 45-56.

32. Wiggs R, Lobprise H. 1997. Periodontology. In: Veterinary dentistry: principles and practice. USA: Lippincott-Raven. $p$ 186-231.

33. Zetner K, Rothmüller G. 2002. The treatment of periodontal pockets with the new perioceutic Doxirobe. Praktischer Tierarzt 3: 214-225.

34. Zetner K, Thiemann G. 1993. The antimicrobial effectiveness of clindamycin in diseases of the oral cavity. J Vet. Dent 10: 6-9. 